\title{
Differential Effects of PACAP-38 on Synaptic Responses in Rat Hippocampal CA1 Region
}

\author{
Marisa Roberto, ${ }^{1,2}$ Rossana Scuri, and Marcello Brunelli \\ Department of Physiology and Biochemistry "G. Moruzzi”, University of Pisa, San Zeno 31, I-56127 Pisa, Italy
}

\begin{abstract}
Pituitary adenylate cyclase-activating polypeptide (PACAP-38) is a member of the vasointestinal polypeptide (VIP)/secretin/glucagon family of neuropeptides for which neuroregulatory functions have been postulated. PACAP-38 receptors are expressed in different brain regions, including hippocampus. In this study, we examined the dose-dependent effects of PACAP-38 on the excitatory postsynaptic field potential (fEPSP) evoked at the Schaffer collateral-CA1 synapse in rat hippocampal slices. Bath application of low dose $(0.05$ $\mathrm{nM}$ ) of PACAP-38 induced long-lasting facilitation of the fEPSP. This enhancement was blocked by the cholinergic receptor antagonist atropine and partially by the NMDA receptor antagonist 2-amino-5-phosphonovalerate (APV) and therefore, shares a common mechanism with LTP. In contrast, a high dose $(1 \mu \mathrm{M})$ of PACAP-38 induced a persistent depression of the fEPSP that was not blocked by antagonists of cholinergic receptors (i.e., atropine and mecamylamine), adenosine receptors (i.e., DCPCX), or glutamatergic NMDA receptors (APV). Intermediate doses $(0.1-0.5 \mu \mathrm{M})$ of PACAP-38 produced an initial decrease of the fEPSP followed by an enhancement. This decrease was not blocked by atropine whereas the facilitation was. These results show that PACAP-38 modulates CA1 synaptic transmission in a dose-dependent manner and that the peptide interacts with cholinergic and glutamatergic systems.
\end{abstract}

Pituitary adenylate cyclase-activating polypeptide (PACAP38 ) is a 38- amino acid peptide that was first isolated from ovine hypothalamus for its ability to stimulate adenylyl cyclase in rat anterior pituitary cells (Arimura 1992). PACAP38 exhibits high sequence identity with vasoactive intestinal peptide (VIP), distinguishing PACAP-38 as a member of the VIP-secretin-glucagon family of peptides. The aminoacid sequence of PACAP-38 has been remarkably conserved during evolution, suggesting that PACAP-38 regulates important physiological functions (Arimura 1992; Masuo et al. 1993). Two receptors for PACAP-38 have been identified: type I receptors, which are positively coupled to adenylyl cyclase and phospholipase $\mathrm{C}$, and type II receptors, which have only been linked to adenylyl cyclase (Spengler et al. 1993). PACAP-38 receptors are mainly distributed in the central nervous system including the hippocampus (Masuo et al. 1992, 1993).

PACAP-38 modulates synaptic activity in several neuronal regions. For example, PACAP-38 enhances in a dosedependent manner the spontaneous release of acetylcholine (ACh) from septal cholinergic fibers in the dorsal hippocampus (Masuo et al. 1993). An excitatory action of PACAP-38 on glutamatergic $N$-methyl-D-aspartate (NMDA) receptors has also been reported in cortical neurons (Martin

\footnotetext{
${ }^{1}$ Present address: The Scripps Research Institute, CVN 12, 10550 N. Torrey Pines Rd., La Jolla, CA 92037.

${ }^{2}$ Corresponding author.

E-MAIL: marisar@dfb.unipi.it; FAX 858-784-7393.

Article and publication are at http://www.learnmem.org/cgi/doi/ $10.1101 / \mathrm{lm} .40501$.
}

et al. 1995; Stella and Magistretti 1996; Liu and Madsen 1997) and in sympathetic preganglionic neurons of neonatal rat (Lai et al. 1997; Wu and Dun 1997). In addition, a high concentration of PACAP-38 (1-3 $\mu \mathrm{M})$ induces a long-lasting depression of the field excitatory postsynaptic potential (fEPSP) at hippocampal CA1 synapses (Kondo et al. 1997).

Recently, we found that a relatively low concentration (0.05 nM) of PACAP-38 enhances the CA1 fEPSPs during baseline synaptic transmission, but not after the induction of long-term potentiation (LTP) produced by tetanic stimulation (Roberto and Brunelli 2000). Atropine, a muscarinic receptor antagonist, blocked the PACAP-induced enhancement of the CA1 fEPSP, suggesting that the PACAP-38 action is mediated by cholinergic muscarinic receptors (Roberto and Brunelli 2000). The PACAP-38 interaction with muscarinic receptors suggests a role of the peptide in learning and memory. Cholinergic pathways are well known to play an important neuromodulatory role in mnemonic functions associated with the hippocampus (Valentino and Dingledine 1981; Brandner and Schenk 1998). One of the predominant effects of muscarinic receptor activation on hippocampal CA1 neurons is potentiation of currents through the NMDA receptors (Madison et al. 1987; Marchi and Raitieri 1989; Markram and Segal 1990; Auerbach and Segal 1994, 1996; Marino et al. 1998).

The aim of the present study was to test the hypothesis that the PACAP-38-induced enhancement of CA1 fEPSPs shares a common mechanism with tetanus-induced LTP at CA1 synapses, and to assess whether the PACAP-38 potentiation was associated with the activation of NMDA receptors. We also further investigated the effect of a higher

LEARNING \& MEMORY 8:265-271 @ 2001 by Cold Spring Harbor Laboratory Press ISSN1072-0502/01 \$5.00

$$
\begin{array}{cllllllllllllll}
L & E & A & R & N & I & N & G \quad & \mathbb{Z} & M & E & M & O & R & Y \\
\text { www.learnmem.org } & \\
& 265
\end{array}
$$


concentration $(1 \mu \mathrm{M})$ of PACAP-38, which previously has been shown to produce a long-lasting depression of transmission at CA1 synapses (Kondo et al. 1997). We found that PACAP-38 produced opposite dose-dependent effects on the CA1 fEPSP. Moreover, PACAP-38 modulated hippocampal synaptic transmission acting, in part, on NMDA receptors. The interaction of PACAP-38 with cholinergic and glutamatergic systems may provide an important mechanism by which the peptide could play a pivotal role in synaptic plasticity thought to underlie learning and memory.

\section{RESULTS}

\section{Tetanic Stimulation Fails to Induce LTP After} PACAP-38-Induced Enhancement of CA1 fEPSPs

Previously, we found that $0.05 \mathrm{nM}$ PACAP-38 produced a long-lasting enhancement of basal CA1 fEPSPs and that this enhancement was occluded by previous induction of LTP by high frequency stimulation (HFS) (Roberto and Brunelli 2000). In the present study, we examined the converse experiment (i.e., whether previous treatment with PACAP38 would occlude LTP). Our results indicate that HFS fails to induce LTP in the presence of $0.05 \mathrm{nM}$ PACAP-38 (Fig. 1). The application of PACAP-38 increased the fEPSP slope to $176 \% \pm 6.5 \%$ compared to the baseline value $(n=8)(P$ $<0.001)$. During the post-tetanic potentiation (PTP, $1 \mathrm{~min}$ after the HFS) the fEPSP slope was $262.9 \% \pm 17.2 \%$. After the saturation of LTP the mean of the fEPSP slope returned near the pretetanic value $(186 \% \pm 7.8 \%, 50 \mathrm{~min}$ after the third HFS) (Fig. 1). In few slices $(n=4)$ after the application of PACAP-38 and before the HFS we readjusted the stimulation intensity (to $40 \%-50 \%$ of the maximal response) (Fig. 2). Under these conditions, the HFS still failed to induce LTP (60 min after the last HFS, the fEPSP slope was $102.3 \% \pm 9.4 \%, P>0.05)$ demonstrating that the occlusion LTP by PACAP-38 effect relative is not due to maximizing the fEPSP. In control slices, the mean percent HFS-induced increase in the dendritic fEPSP slope during PTP and LTP (60 min after the last HFS) relative to baseline (pre-HFS recording) was $272 \% \pm 9 \%$ and $157 \% \pm 6.9 \%(n=11)$, respectively (Fig. 2).

These mutual occlusion experiments indicate that PACAP-38 and afferent tetanic stimulation share a common mechanism for expression of long-term enhancement of synaptic strength.

\section{PACAP-38-Induced Enhancement of CA1 fEPSPs Is Partially Blocked by APV Application}

In the CA1 region of the hippocampus tetanus-induced LTP is dependent on the activation of NMDA receptors (Bliss and Lomo 1973). Because PACAP-38 can directly interact with the NMDA receptors (Liu and Madsen 1997; Wu and Dun 1997), we hypothesized that the mechanisms of PACAP-38-induced enhancement and tetanus-induced LTP

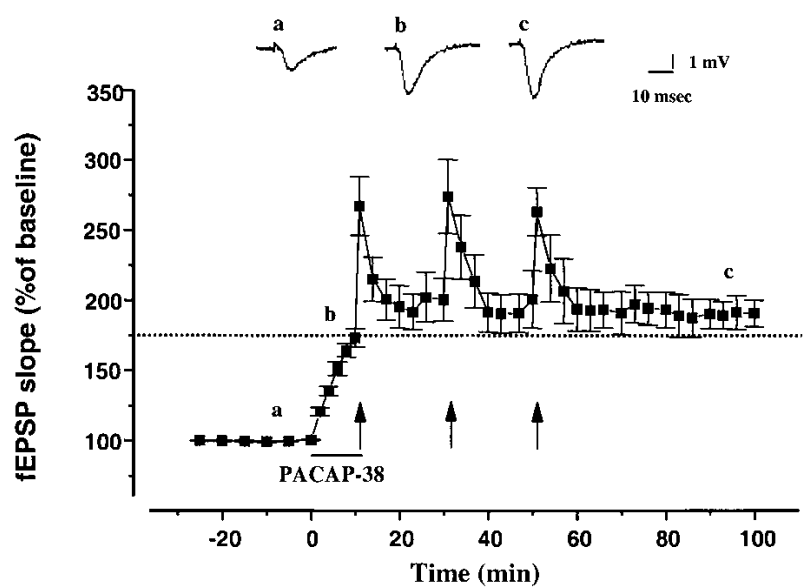

Figure 1 Tetanic stimulation fails to induce LTP after PACAP-38induced enhancement of CA1 fEPSPs. PACAP-38 (0.05 nM) applied for 10 min (solid bar) increased the mean fEPSP slope. Under these conditions, tetanic stimulation (HFS; arrows) induced a transient post-tetanic potentiation of the fEPSP slope, but no LTP. One hour after the post-tetanic potentiation of the third HFS, the fEPSP slope was $186.7 \% \pm 7.8 \%$, which was similar to that with PACAP38 alone ( $P$ \&gt: 0.05). Dotted line represents the level of PACAP38-induced enhancement before HFS. The mean SEM of fEPSP slope are plotted as the percent change over the baseline level. The tetanic LTP was induced by successive trains of HFS $(100 \mathrm{~Hz}, 1 \mathrm{sec}$ duration, 3 trains at 20-min intervals); the arrows denote the points at which the HFS was delivered. Each point plotted is the average of five traces, except for the first point after each HFS, which represents post-tetanic potentiation and an average of a single trace from each experiment. The traces in the inset represent the CA1 synaptic responses to Schaffer-collateral-commissural stimulation (average of five single sweeps) obtained from a slice recorded before (a), during bath application of 0.05 nM PACAP-38 (b), and after the successive trains of HFS (c).

converged at the point of NMDA receptor activation. To investigate the involvement of NMDA receptors in the PACAP-38 action, we tested the effect of 2-amino-5phosphonovalerate (APV) on the PACAP-38-induced potentiation (Fig. 3). The APV attenuated the fEPSP increase produced by PACAP-38 $(0.05 \mathrm{nM})$ in each of five slices tested $(152.10 \% \pm 12.14 \%$; fEPSP slope facilitation induced by 10 min of PACAP-38 application; $122.2 \% \pm 6.2 \%$ fEPSP slope facilitation induced by $10 \mathrm{~min}$ of PACAP-38 application in the presence of APV, $P<0.05$ ) (Fig. 3). Previously, we demonstrated that $0.05 \mathrm{nM}$ PACAP-38-induced a long-lasting enhancement of basal CA1 fEPSPs, which was mediated by the activation of muscarinic receptors, because atropine blocked the PACAP-38 effect (Roberto and Brunelli 2000). The effect of PACAP-38 in the presence of APV was significantly different than the effect of PACAP-38 in the presence of atropine $(1 \mu \mathrm{M})(P \&$ thuinsp; $<0.05)$.

\section{The Effects of Cholinergic and Adenosinergic Antagonists on the Depression of fEPSPs Induced by a High Dose $(1 \mu \mathrm{M})$ of PACAP-38}

In contrast to the facilitatory action of $0.05 \mathrm{nM}$ PACAP-38

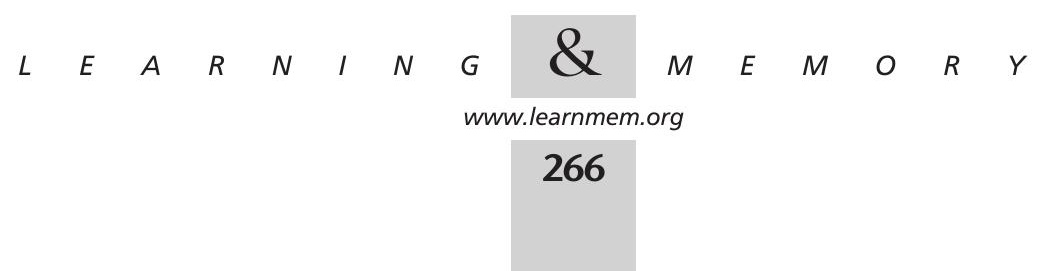




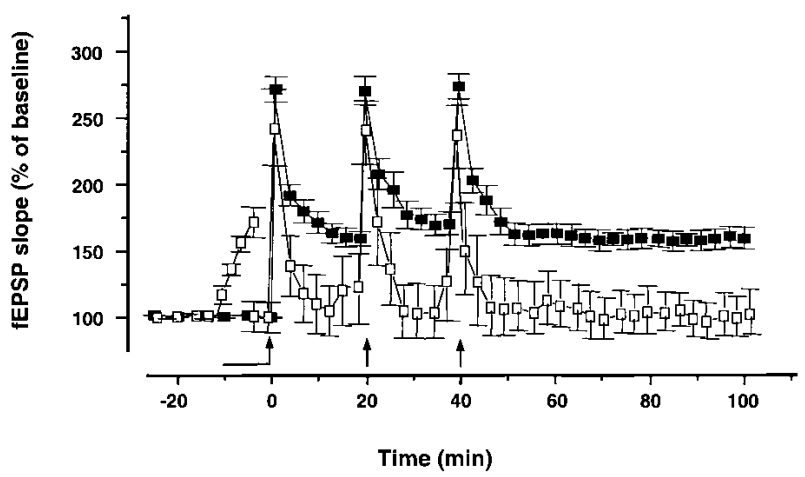

Figure 2 Occlusion LTP by PACAP-38 is not due to maximizing synaptic response. The graph represents pooled data from 11 control slices (solid square), where the LTP was saturated by successive trains of HFS; the arrows denote the points at which the HFS was delivered. In four slices, in which 0.05 nM PACAP-38 applied for $10 \mathrm{~min}$ (solid bar) increased the mean fEPSP slope to $175 \% \pm 5.5 \%$ $(P<0.001)$ compared to the baseline value, we readjusted the stimulation intensity to the $40 \%-50 \%$ of maximal response before the application of the first HFS in presence of PACAP-38 (open square). The HFS induced only the PTP (at $1 \mathrm{~min}$ after the first tetanic stimulation fEPSP slope was $243 \% \pm 13.7 \%, P<.001)$ and failed to induce LTP (at $60 \mathrm{~min}$ after the last HFS the fEPSP slope was $102.3 \% \pm 9.4 \%, P>0.05)$. The mean SEM of fEPSP slope are plotted as the percent change over the baseline level. Each point plotted is the average of five traces, except for the first point after each HFS, which represents post-tetanic potentiation and an average of a single trace from each experiment.

observed in our studies (see above), Kondo et al. (1997) showed that $1 \mu \mathrm{M}$ PACAP-38 depressed the CA1 fEPSP. Therefore, we investigated the effect of high dose of PACAP-38. We confirmed the observations of Kondo et al. that $1 \mu \mathrm{M}$ PACAP-38 induced a long-lasting depression of transmission at CA1 synapses. Bath application of PACAP-38 (10 min) caused a rapid reduction of fEPSP slope ( $8 \% \pm 11.2 \%$ of control, $n=6$ ) (Fig. 4). The depression of the synaptic responses lasted during the washout (Fig. 5). To assess the possible contribution of cholinergic receptors to the depression induced by a high concentration of PACAP-38 we applied $1 \mu \mathrm{M}$ PACAP-38 together with cholinergic muscarinic and nicotinic blockers (Fig. 4). The depressive effect of $1 \mu \mathrm{M}$ of PACAP-38 was not significantly blocked by $1 \mu \mathrm{M}$ of atropine $(n=9)$ or $1 \mu \mathrm{M}$ of mecamylamine $(n=8)$ (Fig. 4). Nor was it blocked by APV $(n=7)$ (Fig. 4).

Because the PACAP-38 receptors are linked to adenylyl cyclase (Splenger et al. 1993), their activation may lead to enhanced production of adenosine and subsequent activation of adenosine receptors (Scholz and Miller 1991; Gereau and Conn 1994). To examine this hypothesis, we applied PACAP-38 in the presence of the A1 adenosine receptor blocker DPCPX. In the presence of DPCPX, the long-lasting depression induced by $1 \mu \mathrm{M}$ PACAP-38 was not altered significantly (Fig. 4).

\section{Intermediate Doses of PACAP-38 Produces an Initial Decrease of fEPSPs Followed by an Enhancement. Atropine Does not Alter the Depressive Effect of PACAP-38 but Blocked the Enhancement}

Given that low concentrations enhance fEPSP and high concentrations attenuate fEPSP, we predicted that intermediate concentrations would produce mixed responses. To test this hypothesis we reduced the concentration $(0.5,0.25$, $0.1 \mu \mathrm{M})$ and the duration ( $5 \mathrm{~min}$ ) of PACAP-38 application. This brief bath application of intermediate doses induced a biphasic effect on the fEPSP in all slices analyzed. There was an initial depression followed by an enhancement during the washout. The magnitude of these effects was concentration-dependent (Fig. 5). After 5 min of $0.5 \mu \mathrm{M}$ PACAP-38
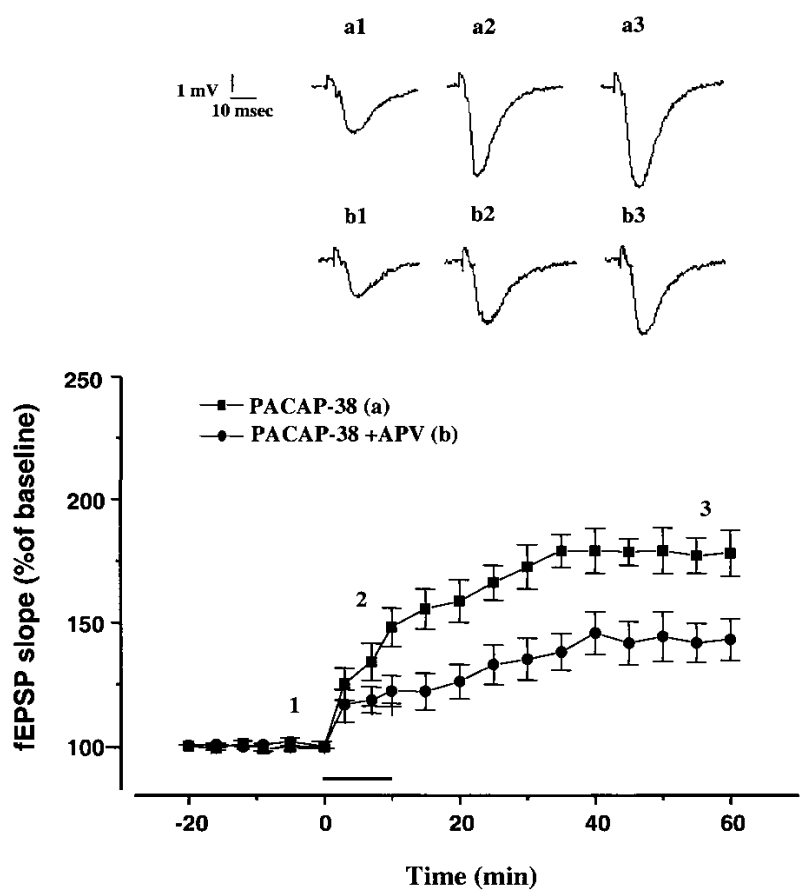

Figure 3 The NMDA receptor antagonist APV attenuates the PACAP-38-induced enhancement of CA1 fEPSPs. The APV was applied to the slices 10-15 min before and throughout application of $0.05 \mathrm{nM}$ PACAP-38. The APV $(30 \mu \mathrm{M})$ significantly reduced PACAP-38-induced enhancement of fEPSP. At $10 \mathrm{~min}$ of PACAP38 bath application, the percentage change in fEPSP slope was $122.2 \% \pm 6.2 \%(n=5 ; P<0.05)$ in the slices treated with APV plus PACAP-38, which was smaller than in the slices treated with PACAP-38 alone $(152.10 \% \pm 12.14 \% ; n=9)$. At 50 min of washout from PACAP-38 and APV, the fEPSP slope was $143 \% \pm 8.5 \%$ $(n=5 ; P<0.05)$ (in the slices treated only with PACAP-38, at the same timepoint the fEPSP slope was $178.0 \% \pm 9.35 \% ; n=9 ; P$ $<0.05)$. The mean SEM of fEPSP slope are plotted as the percent change over the baseline level. (Inset) The traces represent the CA1 synaptic responses (average of five single sweeps) obtained from: (Top) a slice recorded before (a1), during (a2), and after bath application of 0.05 nM PACAP-38 (a3) and (bottom) a slice recorded during the APV application (b1) during the coapplication of 0.05 nM PACAP-38 and $30 \mu \mathrm{M} \mathrm{APV} \mathrm{(b2),} \mathrm{and} \mathrm{in} \mathrm{the} \mathrm{washout} \mathrm{(b3).}$

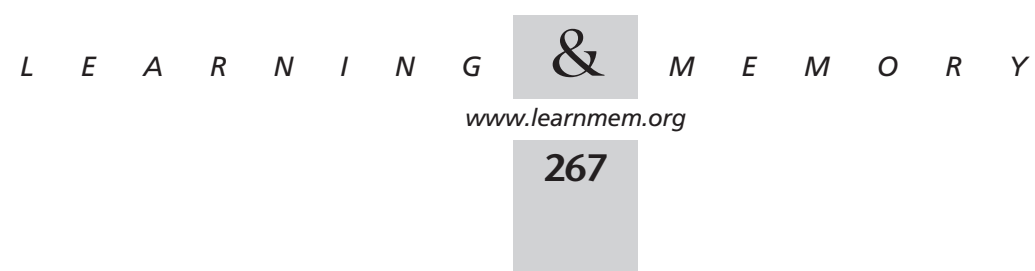




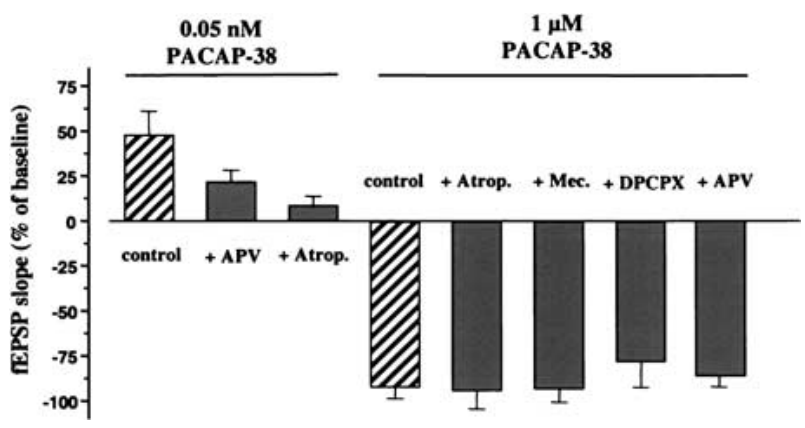

Figure 4 Effects of cholinergic and adenosinergic antagonists on the PACAP-38-induced depression of the fEPSP. The histograms (right) show the effects of PACAP-38 $(1 \mu \mathrm{M}, 10$-min application) on the fEPSP slope in the absence of antagonists (control) or in the presence of atropine $(1 \mu \mathrm{M})$, a nonspecific muscarinic cholinergic receptor antagonist (+ Atrop.), mecamylamine $(1 \mu \mathrm{M})$, a nicotinic receptor antagonist or $(+\mathrm{Mec}$.$) , or in presence of DPCPX (1 \mu \mathrm{M})$, a selective A1 adenosine receptor antagonist (+ DPCPX), or APV (30 $\mu \mathrm{M})$, a selective glutamatergic NMDA receptor antagonist (+ APV). The antagonists were applied to the slices 10-15 min before and 10 min simultaneously with $1 \mu \mathrm{M}$ PACAP. To help clarify the dosedependent effects of PACAP-38, the histograms to the left show the effects of APV and atropine on the low dose of PACAP-38 (0.05 $n M)$.

application the fEPSP slope was depressed to $6.7 \% \pm 3.6 \%$ of the baseline $(P<0.05)$ (Fig. 5$)$. This depression was not long lasting. During the washout a facilitatory effect appeared. After $15 \mathrm{~min}$ of washout, the enhancement of fEPSPs reached levels of $158.6 \% \pm 14.6 \%(P<0.05)$ and remained at that stable facilitated level (Fig. 5). The application of $0.25 \mu \mathrm{M}$ and $0.1 \mu \mathrm{M}$ of PACAP-38 depressed the fEPSP slope to $24.3 \% \pm 7.6 \%$ and $75.1 \% \pm 9 \%$, respectively, of the baseline ( $n=7$ and $n=6, P<0.05$ ) (Fig. 5). At 15 min of washout in the slices treated with $0.25 \mu \mathrm{M}$ and 0.1 $\mu \mathrm{M}$ of PACAP-38, the mean fEPSP slope was $149.6 \% \pm 4.5 \%$ and $118.3 \% \pm 8.7 \%$, respectively, compared to the control value.

In addition, atropine did not block the initial depression of fEPSP, but prevented the late enhancement produced by $0.5 \mu \mathrm{M}$ of PACAP-38 and unmasked a long-lasting depression (Fig. 6).

\section{DISCUSSION}

Previously, we reported that brief bath application of 0.05 $\mathrm{nM}$ of PACAP-38 induced a long-lasting enhancement of the Schaffer collateral-commissural CA1 fEPSP, whereas PACAP38 produced only a transient increase in the evoked responses after LTP was saturated (Roberto and Brunelli 2000). In those studies atropine blocked both facilitatory effects (Roberto and Brunelli 2000).

In the present paper, we show that tetanic stimulation failed to induce LTP after PACAP-induced enhancement of the CA1 fEPSP. These mutual occlusion experiments indicate that PACAP-38 and HFS enhance CA1 fEPSP through a common mechanism. The enhancement might be due to a postsynaptic regulation of NMDA responses through the activation of muscarinic receptors (Marino et al. 1998) or directly at the PACAP-38 receptor (Liu and Madsen 1997; Wu and Dun 1997). Therefore, to determine the involvement of NMDA receptors we applied APV to block the NMDA receptors. The APV $(30 \mu \mathrm{M})$ markedly reduced, but did not completely block, the fEPSP enhancement produced by $0.05 \mathrm{nM}$ of PACAP-38. The effect of APV was less than the effect of atropine, suggesting that some of PACAP38/muscarinic effects on fEPSPs are mediated by NMDA receptor-independent mechanisms. The facilitatory action of PACAP-38 might be attributable to a synergistic effect of cross-talk between different biochemical pathways by the combined activation of PACAP-38 receptors and muscarinic receptors. In future experiments, we plan to investigate the role of intracellular $\mathrm{Ca}^{2+}$ and the adenylyl cyclase cascade in these interactions.

PACAP-38 enhances in a dose-dependent manner the spontaneous release of ACh from the septal cholinergic fibers in the dorsal hippocampus (Masuo et al. 1993) and ACh evokes multiple, concentration-dependent, effects on evoked responses at CA1 synapses (Bernardo and Prince 1982; Madison et al. 1987). Specifically, ACh can induce a long-lasting muscarinic enhancement of EPSPs (Krnjevic et al. 1981; Marchi and Raitieri 1989; Blitzer et al. 1990; Markram and Segal 1990; Auerbach and Segal 1994) as well as a suppression of the CA1 responses evoked by stimulation of Schaffer collateral-commissural fibers (Krnjevic et al. 1981; Krnjevic and Report 1982; Sheridan and Sutor 1990; Auerbach and Segal 1996). As PACAP-38 enhancement is

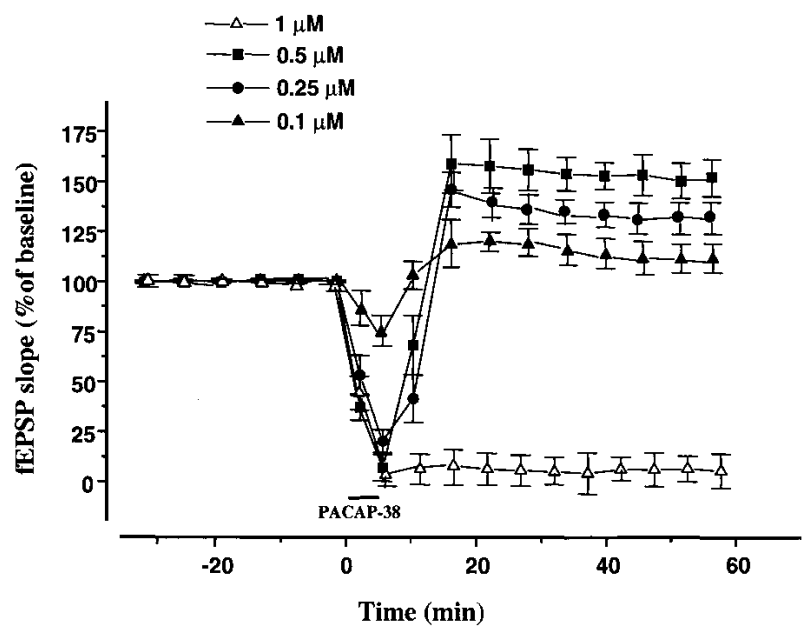

Figure 5 Biphasic effects of intermediate doses of PACAP-38. Brief (5 min) bath application of intermediate doses $(0.5,0.25,0.1$ $\mu \mathrm{M})$ of PACAP-38 induced a biphasic effect on fEPSPs in all slices analyzed. There was an initial depression followed by an enhancement during the washout period. The magnitude of these effects was concentration-dependent. In the slices, in which $1 \mu \mathrm{M}$ PACAP38 applied for $10 \mathrm{~min}$ (open triangle), the depression was longlasting. The mean SEM of fEPSP slope are plotted as the percent change over the baseline level.

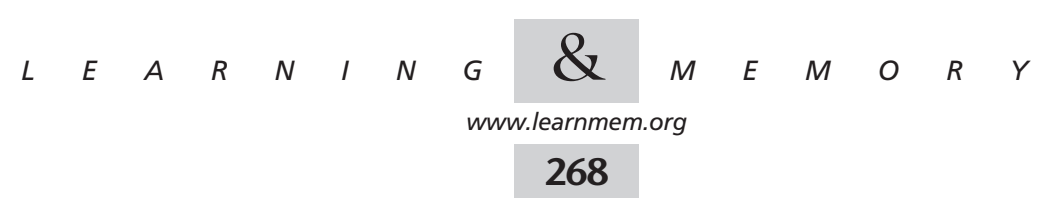



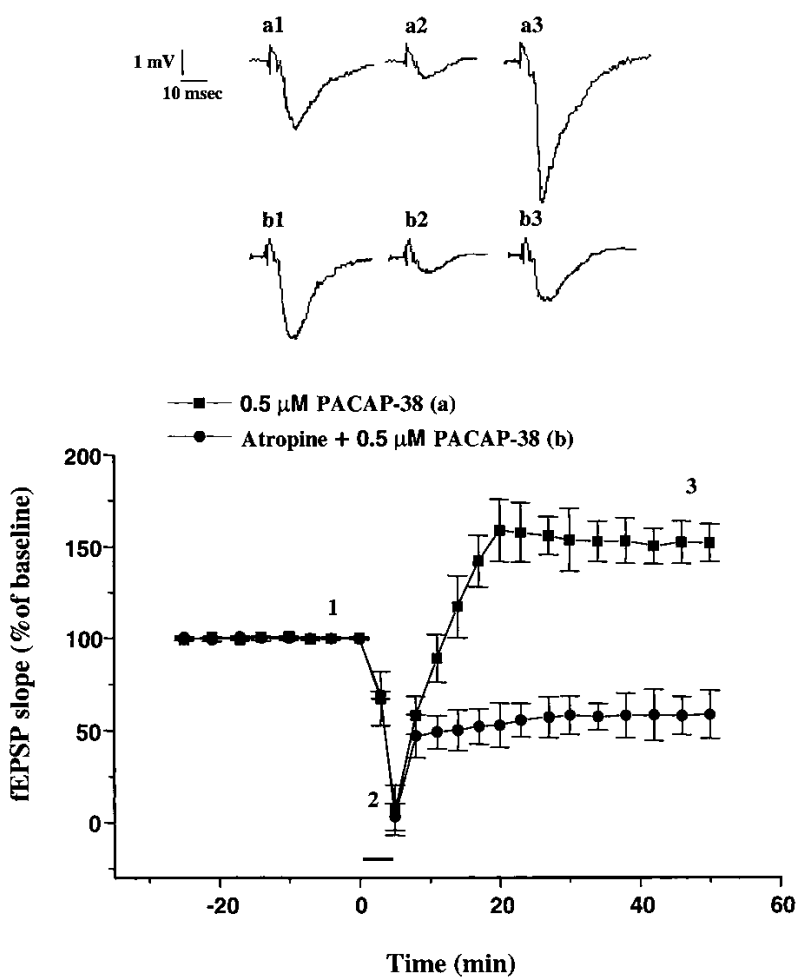

Figure 6 Atropine blocks the late enhancement of CA1 fEPSP produced by an intermediate dose of PACAP-38. Superfusion with $0.5 \mu \mathrm{M}$ of PACAP-38 for 5 min caused a rapid and transient depression of the fEPSP slope $(6.67 \% \pm 3.67 \%, P<0.05)$, followed by a long-lasting facilitation of the fEPSP $(158.6 \% \pm 14.6 \%, n=4$, $P<0.05)$. Atropine $(1 \mu \mathrm{M})$ did not block the depression induced by PACAP application at $0.5 \mu \mathrm{M}$ but blocked the facilitation. Note that in the slices treated with atropine the depression was long lasting on washout. The mean SEM of fEPSP slope are plotted as the percent change over the baseline level. (Inset) Representative records of fEPSP obtained from traces represent the CA1 synaptic responses (average of five single sweeps) obtained from: (Top) a slice recorded before (a1), during (a2), and after bath application of 0.5 $\mu \mathrm{M}$ PACAP-38 (a3) and (bottom) a slice recorded during $1 \mu \mathrm{M}$ atropine application (b1) during the coapplication of $0.5 \mu \mathrm{M}$ PACAP-38 and $1 \mu \mathrm{M}$ atropine (b2), and in the washout (b3).

mediated by cholinergic receptors, we investigated the possible involvement of this pathway in the PACAP-38-induced depression. Atropine and mecamylamine did not block the PACAP-38-induced depression, demonstrating that this effect is not dependent on cholinergic transmission. The APV also did not block the depressive effect of PACAP-38. This result is consistent with the Kondo et al. (1997) report showing that NMDA receptors are not involved in this PACAP-38 effect. Blockade of A1 receptors did not prevent the PACAP-38-induced depression, showing that the involvement of CAMP metabolites are not required to depress the synaptic transmission in CA1 region (Scholz and Miller 1991; Gereau and Conn 1994).

In our study the depressive effect of PACAP-38 $(1 \mu \mathrm{M})$ was stronger than the effect reported by Kondo et al. This might be due to the different age of the rats used in the two studies (Kondo et al. 1997). We exclude a nonspecific damage of the tissue, as the presynaptic component was preserved, although the peptide caused a nearly complete abolishment of fEPSPs. In fact, the increase of the stimulation intensity was correlated to an increase of presynaptic volley amplitude showing the functionality of the synapse (data not shown). We reduced both the dosage and the time of application of PACAP-38. Interestingly, shorter ( $5 \mathrm{~min}$ ) bath application of (0.5-0.1 $\mu \mathrm{M})$ PACAP-38 exhibited an initial depression followed by an enhancement of the fEPSP. The late facilitation seems to be inhibition-dependent, suggesting a mechanism of postinhibitory rebound. Atropine did not alter the initial PACAP-induced depression, but blocked significantly the PACAP-induced late enhancement of the fEPSP. Although, muscarinic receptors are also involved in this facilitatory effect, the intracellular pathways underlying the two types of facilitation (low-dose PACAP-induced enhancement and high-dose PACAP-induced late enhancement) may be different. If the facilitation after inhibition was merely due to the residual (low) concentrations of PACAP-38 remaining in the slice, then this effect should be seen at all three doses. Further studies are needed to clarify these issues.

An important question is: How does PACAP-38 induce different effects at different dosages? The PACAP-38 receptors are currently grouped into at least two types on the basis of their affinities for PACAP and VIP: type I receptor that can activate adenylyl cyclase and stimulate phospholipase $\mathrm{C}$ leading to increased intracellular cyclic AMP (cAMP), inositol triphosphate (IP3)-mediated calcium mobilitazation, and calcium and diacylglycerol (DAG)-mediated protein kinase C (PKC) activation, and type II receptor that is coupled to adenylyl cyclase alone (Splenger et al. 1993). Type I binding sites exhibit high affinity for PACAP and much lower affinity for VIP; type II binding sites possess similar affinity for PACAP and VIP (Gottschall et al. 1990, Vaudry et al. 2000). High levels of type I and type II binding sites occur in the cholinergic septohippocampal terminals and a high concentration of type I binding sites is also observed in the pyramidal cells of the hippocampus. Thus, various signal transduction pathways elicited by activation of PACAP-38 receptors may differ at different doses and explain the opposite effects. Intracellular recordings are underway to determine whether these PACAP-38 differential effects are due to different intracellular mechanisms.

In conclusion, in this report we have demonstrated that the peptide PACAP-38 can differentially modulate synaptic strength in a concentration-specific manner. The enhancement of the CA1-evoked response is mediated by both muscarinic and NMDA receptors. In addition, the long-lasting PACAP-38 (0.05 nM)-induced enhancement and the expression of LTP share in part a common mechanism that involves the activation of NMDA receptors. Because PACAP-

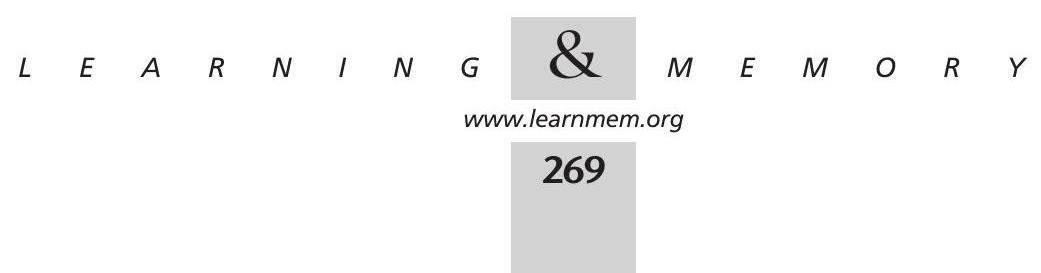


38 interacts with cholinergic and glutamatergic systems, it may modulate these two neurotransmitter pathways and the wide variety of synaptic forms of plasticity dependent on their activation. Consequently, PACAP-38 may play an important role in the modulation of learning and memory processes.

\section{MATERIALS AND METHODS}

The experiments were performed on transverse hippocampal slices $(400 \mu \mathrm{m})$ obtained from Wistar rats (100-180 g). Hippocampal slices were prepared as described previously (Roberto and Brunelli 2000). Animals were anesthetized with halothane (3\% in air) and then decapitated. The brain was rapidly excised and cut using a vibroslicer (Campden Instruments Ltd). Slices were stored at room temperature for at least $60 \mathrm{~min}$ in artificial cerebrospinal fluid (aCSF) of the following composition (in $\mathrm{mM}$ ): $\mathrm{NaCl}, 130 ; \mathrm{KCl}$, 3.5; $\mathrm{NaH}_{2} \mathrm{PO}_{4}, 1.25 ; \mathrm{MgSO}_{4}, 1.5 ; \mathrm{CaCl}_{2}, 2 ; \mathrm{NaHCO}_{3}, 24$; glucose, 10 ; and gassed with a $95 \% \mathrm{O}_{2}-5 \% \mathrm{CO}_{2}$ gas mixture at $\mathrm{pH} 7.4$. For recording slices were transferred to a submerged recording chamber for experiments and perfused with aCSF at a rate of $2 \mathrm{~mL} / \mathrm{min}$ at $30^{\circ}-32^{\circ} \mathrm{C}$.

Excitatory postsynaptic field potentials were recorded extracellularly from the apical dendritic layer of CA1 (stratum radiatum) with a glass micropipette (2-5 M $\Omega$ ) filled with aCSF (Roberto and Brunelli 2000). The signals were amplified and filtered (DC-3 $\mathrm{KHz}$ ) using an amplifier (Biomedica Mangoni, 612P). The data were stored on a PC for data analysis using software developed with LABVIEW (National Instruments). Bipolar electrodes (SNEX-200, Rhodes Med. Instr.) were used for stimulation of Schaffer collateralcommissural afferent fibers. The intensity of the test stimulus, delivered at $0.033 \mathrm{~Hz}$, was adjusted for each slice so that the fEPSP was equal to $\sim 40 \%-50 \%$ of the maximal amplitude of the fEPSP. Only slices in which fEPSPs were constant for 20-30 min were used in this study. Evoked responses were averaged from five sweeps and the slope of the fEPSP was measured. Compiled data were expressed as the mean \pm SEM. Statistical analysis was done using a one-factor ANOVA with repeated measures followed by a Fisher's post-hoc test. Statistical significance was set at $P<0.05$.

Saturation of LTP was induced by successive trains of HFS $(100 \mathrm{~Hz}, 1-\mathrm{sec}$ duration, 3 trains at 20-min intervals) at the same intensity of the test stimulus until no additional potentiation was elicited. In control slices, HFS of the Schaffer collaterals consistently produced PTP of the synaptic response that lasted 1-5 min and that was followed by LTP that lasted a minimum of $60 \mathrm{~min}$.

PACAP-38 was dissolved in acetic acid (5\%) then added to aCSF (final acetic acid concentration $0.005 \%$ ). Atropine, a nonspecific muscarinic receptor antagonist, and mecamylamine, a nicotinic receptor antagonist, were dissolved directly in aCSF. The APV was prepared as a stock solution in distilled water and diluted in aCSF. DPCPX, a selective A1 adenosine receptor antagonist, was dissolved in dimethylsulfoxide (DMSO; 0.1\%) then added to aCSF (final DMSO concentration 0.01\%). Vehicle controls of acetic acid or DMSO demonstrated no observable effects on synaptic transmission. Atropine, mecamylamine, and DPCPX when used, were applied in the bath for 10-15 min before the application of PACAP-38, and during PACAP-38 application.

\section{ACKNOWLEDGMENTS}

We are grateful to F. Montanari and E. Cardaci for technical assistance, and to G. Bresciani for animal care. We gratefully acknowl- edge Drs. Melanie Tallent and Jeff Netzeband for valuable discussions. This study was supported by the University Grant Research Support (60\%) and Fondazione della Cassa di Risparmio di Volterra.

The publication costs of this article were defrayed in part by payment of page charges. This article must therefore be hereby marked "advertisement" in accordance with 18 USC section 1734 solely to indicate this fact.

\section{REFERENCES}

Arimura, A. 1992. Receptors for pituitary adenylate cyclase-activating polypeptide. Comparison with vasoactive intestinal peptide receptors Trends Endocrinol. Metab. 3: 288-294.

Auerbach, J.M. and Segal, M. 1994. A novel cholinergic induction of long-term potentiation in rat hippocampus. J. Neurophysiol. 72: 2034-2040.

- 1996. Muscarinic receptors mediating depression and long-term potentiation in rat hippocampus. J. Neurophysiol. 492: 479-493.

Bernardo, L.S. and Prince, D.A. 1982. Ionic mechanisms of cholinergic excitation in mammalian hippocampal pyramidal cells. Brain Res. 249: 333-344

Bliss, T.V.P. and Lomo, T. 1973. Long-lasting potentiation of synaptic transmission in the dentate area of anaesthetized rabbit following perforant path stimulation. J. Neurophysiol. 232: 331-356.

Blitzer, R.D., Gil, O., and Landau, E.M. 1990. Cholinergic stimulation enhances long-term potentiation in the CA1 region of rat hippocampus. Neurosci. Lett. 119: 207-210.

Brandner, C. and Schenk, F. 1998. Septal lesions impair the acquisition of cued place navigation task: Attentional or memory deficits? Neurobiol. Learn. Mem, 69: 106-125.

Gereau, R.W. IV and Conn, P.J. 1994. Potentiation of cAMP responses by metabotropic glutamate receptors depresses excitatory synaptic transmission by a kinase-independent mechanism. Neuron 12: 1121-1129.

Gottschall, P.E., Tatsuno, I., Myyata, A., and Arimura, A. 1990. Characterization and distribution of binding sites for hypothalamic peptide, pituitary adenylate cyclase-activating polypeptide. Endrocrinology 127: 272-277.

Kondo, T., Tominaga, T., Ichikawa, M., and Iijima, T. 1997. Differential alteration of hippocampal synaptic strength induced by pituitary adenylate cyclase activating polypeptide-38 (PACAP-38). Neurosci. Lett. 221: 189-192.

Krnjevic, R.P. and Ropert, N. 1982. Electrophysiological and pharmacological characteristics of facilitation of hippocampal population spikes by stimulation of the medial septum. Neuroscience 7: 2165-2183

Krnjevic, R.P., Reiffenstein, R.J., and Ropert, N. 1981. Disinihibitory action of acetylcholine in the rats' hippocampus: Extracellular observations. Neuroscience 6: 2465-2474.

Lai, C.C., Wu, S.Y., Lin, H.H., and Dun, N.J. 1997. Excitatory action of pituitary adenylate cyclase activating polypeptide on rat sympathetic preganglionic neurons in vivo and in vitro. Brain Res. 748: 189-194.

Liu, G.J. and Madsen, B.W. 1997. PACAP-38 modulates activity of NMDA receptors in cultured chick cortical neurons. J. Neurophysiol. 78: 2231-2234.

Madison, D.V., Lancaster, B., and Nicoll, R.A. 1987. Voltage clamp analysis of cholinergic action in the hippocampus. J. Neurosci. 7: 733-741.

Marchi, M. and Raitieri, M. 1989. Interaction acetylcholine-glutamate in rat hippocampus: Involvement of two subtypes of M-2 muscarinic receptor. J. Pharmacol. Exp. Ther. 248: 1255-1260.

Marino, M.J., Rouse, S.T., Levey, A., Potter, L.T., and Conn, J. 1998. Activation of genetically $\mathrm{m} 1$ muscarinic receptor potentiates $N$-methyl-D-aspartate (NMDA) receptor currents in hippocampal pyramidal cells. Proc. Natl. Acad. Sci. 95: 11465-11470.

Markram, H. and Segal, M. 1990. Long-lasting facilitation of excitatory postsynaptic potentials in the rat hippocampus by acetylcholine. $J$. Physiol. 427: 381-393.

Martin, J-L., Gasser, D., and Magistretti, P.J. 1995. Vasoactive intestinal

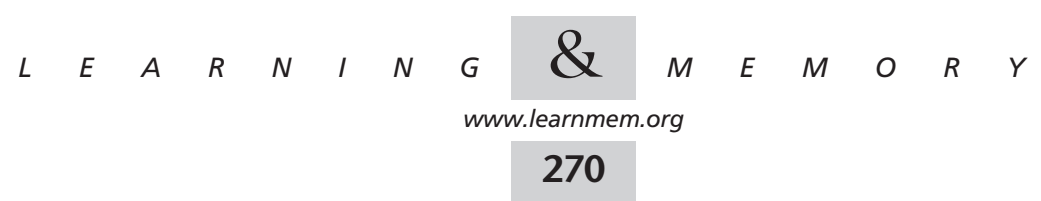


peptide and pituitary adenylate cyclase-activating polypeptide potentiate $c$-fos expression induced by glutamate in cultured cortical neurones. J. Neurochem. 65: 1-9.

Masuo, Y., Ohtaki, T., Masuda, Y., and Fujino, M. 1992. Binding sites for pituitary adenylate cyclase activating polypeptide (PACAP): Comparison with vasoactive intestinal polypeptide (VIP) binding site localization in rat brain. Brain Res. 575: 113-123.

Masuo Y., Matsumoto, Y., Tokito, F., Tsuda, M., and Fujino, M. 1993. Effects of vasoactive intestinal polypeptide (VIP) and pituitary adenylate cyclase activating polypeptide (PACAP) on the spontaneous release of acetylcholine from hippocampus by brain microdialysis. Brain Res. 611: 207-215.

Roberto, M. and Brunelli, M. 2000. Pacap-38 enhances excitatory synaptic transmission in rat hippocampal CA1 region. Learn. Mem. 7: 303-311.

Scholz, K.P. and Miller, R.J. 1991. Analysis of adenosine actions on Ca 2+ currents and synaptic transmission in cultured rat hippocampal pyramidal neurones. J. Physiol. 435: 373-393.

Sheridan, R.D. and Sutor, B. 1990. Presynaptic M1 muscarinic cholinoceptors mediate inhibition of excitatory synaptic transmission in the hippocampus in vitro. Neurosci. Lett. 22: 273-278.
Spengler, D., Waeber, C., Pantaloni, C., Holsboer, F., Bockaert, J., Seeburg, P.H., and Journot, L. 1993. Differential signal transduction by five splice variants of the PACAP receptor. Nature 365: 170-175.

Stella, N. and Magistretti, P.J. 1996. Vasoactive intestinal polypeptide (VIP) and pituitary adenylate cyclase activating polypeptide (PACAP) potentiate the glutamate-evoked release of arachidonic acid from mouse cortical neurones. J. Biol. Chem. 271: 23705-23710.

Valentino, R.J. and Dingledine, R. 1981. Presynaptic inhibitory effect of acetylcholine in the hippocampus. J. Neurosci. 1: 784-792.

Vaudry, D., Gonzalez, B.J., Basille, M., Yon, L., Fournier, A., and Vaudry, H. 2000. Pituitary adenylate cyclase-activating polypeptide and its receptors: From stucture to functions. Pharmacol. Rev. 52: 269-324.

Wu, S.Y. and Dun, N. J. 1997. Potentiation of NMDA currents by pituitary adenylate cyclase-activating polypeptide in neonatal rat sympathetic preganglionic neurons. J. Neurophysiol. 78: 1175-1179.

Received April 19, 2001; accepted in revised form July 30, 2001.

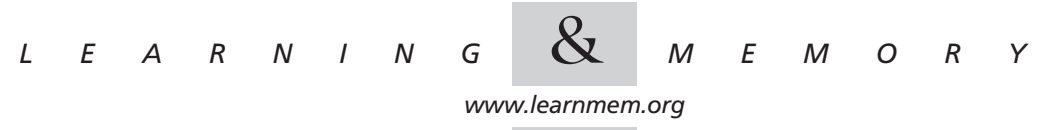




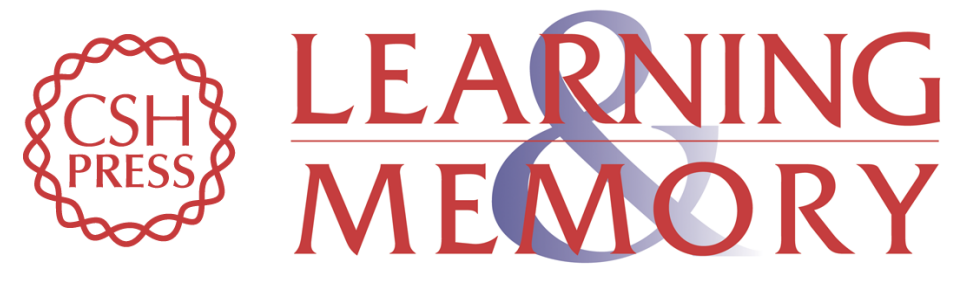

\section{Differential Effects of PACAP-38 on Synaptic Responses in Rat Hippocampal CA1 Region}

Marisa Roberto, Rossana Scuri and Marcello Brunelli

Learn. Mem. 2001, 8:

Access the most recent version at doi:10.1101//m.40501

References This article cites 29 articles, 7 of which can be accessed free at:

http://learnmem.cshlp.org/content/8/5/265.full.html\#ref-list-1

License

Email Alerting Receive free email alerts when new articles cite this article - sign up in the box at the Service top right corner of the article or click here. 